\title{
Inundação em mudas de jabuticabeira
}

Flood in jaboticaba tree seedlings

Inundación en plántulas de jaboticaba

Recebido: 11/11/2020 | Revisado: 19/11/2020 | Aceito: 23/11/2020 | Publicado: 28/11/2020

\section{Juliana Cristina Radaelli}

ORCID: https://orcid.org/0000-0002-8391-1795

Universidade Tecnológica Federal do Paraná, Brasil

E-mail: julianaradaelli@gmail.com

Karina Guollo

ORCID: https://orcid.org/0000-0002-5308-3773 Universidade Tecnológica Federal do Paraná, Brasil E-mail: engkarinaguollo@ hotmail.com

Carlos Kosera Neto

ORCID: https://orcid.org/0000-0002-7201-1732

Universidade Tecnológica Federal do Paraná, Brasil E-mail: eng.agr.carloskosera@gmail.com

Marciéli da Silva

ORCID: https://orcid.org/0000-0002-3807-6727

Universidade Tecnológica Federal do Paraná, Brasil

E-mail: marcielidasilva@hotmail.com

Fabiano Simões

ORCID: https://orcid.org/0000-0001-5995-3330 Universidade Estadual do Rio Grande do Sul, Brasil

E-mail: fabiano-simoes@uergs.edu.br

Américo Wagner Junior

ORCID: https://orcid.org/0000-0001-5081-5281

Universidade Tecnológica Federal do Paraná, Brasil

E-mail: americowagner@utfpr.edu.br

\section{Resumo}

O objetivo deste trabalho foi avaliar o estresse hídrico em mudas de jabuticabeira por meio da inundação das plantas por diferentes períodos e lâminas de água. Dois experimentos com 
mudas de jabuticabeira foram instalados, no primeiro as mudas com 18 meses foram submetidas a lâmina de água de cinco centímetros, por um período de $0,3,5,10$ e 15 dias ou por dois períodos de 3, 5, 10 e 15 dias após intervalo de 30 dias. No segundo experimento, as mudas com 24 meses, foram inundadas por água até altura do colo, por períodos de $0,5,10 \mathrm{e}$ 15 dias, ou por dois períodos de 5, 10 e 15 dias após intervalo de 30 dias. Tais condições visam representar estresse hídrico por inundação. Sendo avaliadas variáveis biométricas como, número de folhas, diâmetro do caule, tamanho total, massa seca das raízes e da parte aérea e massa da matéria seca total. As determinações fisiológicas foram teor de clorofila total e rendimento quântico. As variáveis bioquímicas foram teor de proteínas, teor de açúcares totais, fenóis totais e prolina. $\mathrm{O}$ crescimento das mudas de jabuticabeira não foi afetado pelos períodos de inundação adotados para os experimentos com diferentes capacidades de campo. Nos tratamentos em que as plantas foram submetidas aos dois ciclos de inundação com lâmina de água a altura do colo apresentaram diferenças significativas no incremento em número de folhas, altura da muda e diâmetro do caule o que consequentemente alterou a massa seca da parte aérea.

Palavras-chave: Plinia spp.; Alagamento; Estresse abiótico; Frutas nativas.

\begin{abstract}
The aim of this work was to evaluate the water stress in jabuticaba seedlings by flooding the plants for different periods and water depths slide. Two experiments with jaboticaba trees seedlings were installed, in the first, the seedlings aged 18 months were submitted to a $5 \mathrm{~cm}$ water slide, for a period of $0,3,5,10$ and 15 days or for two periods of $3,5,10$ and 15 days after a 30-day interval. In the second experiment, the seedlings at 24 months were flooded with water until the height of the colon, for periods of $0,5,10$ and 15 days, or for two periods of 5, 10 and 15 days after a 30-day interval. Such conditions aim to represent water stress due to flooding. Biometric variables such as number of leaves, stem diameter, total size, dry weight of roots and shoots and total dry matter were evaluated. The physiological determinations were total chlorophyll content and quantum yield. The biochemical variables were protein content, total sugar content, total phenols and proline. The growth of jabuticaba trees was not affected by the flood periods adopted for experiments with different field capacities. In the treatments in which the plants were subjected to the two water cycle flooding, the height of the stem showed significant differences in the increase in number of leaves, height of the seedling and diameter of the stem, which consequently altered the dry mass of the aerial part.
\end{abstract}


Keywords: Plinia spp.; Flooding; Abiotic stress; Native fruits.

\section{Resumen}

El objetivo de este trabajo fue evaluar el estrés hídrico en plántulas de jabuticaba al inundar las plantas por diferentes períodos y profundidades de agua. Se instalaron dos experimentos con plántulas de jaboticaba, en el primero, las plántulas de 18 meses se sometieron a un tobogán de agua de $5 \mathrm{~cm}$, por un período de $0,3,5,10$ y 15 días o por dos períodos de $3,5,10$ y 15 días después de un intervalo de 30 días. En el segundo experimento, las plántulas a los 24 meses se inundaron con agua hasta la altura del colon, por períodos de $0,5,10$ y 15 días, o por dos períodos de 5, 10 y 15 días después de un intervalo de 30 días. Tales condiciones apuntan a representar el estrés hídrico debido a las inundaciones. Se evaluaron variables biométricas como número de hojas, diámetro del tallo, tamaño total, peso seco de raíces y brotes y materia seca total. Las determinaciones fisiológicas fueron el contenido total de clorofila y el rendimiento cuántico. Las variables bioquímicas fueron contenido de proteína, contenido de azúcar total, fenoles totales y prolina. El crecimiento de los árboles de jabuticaba no se vio afectado por los períodos de inundación adoptados para experimentos con diferentes capacidades de campo. En los tratamientos en los que las plantas fueron sometidas a la inundación de los dos ciclos hídricos, la altura del tallo mostró diferencias significativas en el aumento en el número de hojas, altura de la plántula y diámetro del tallo, lo que consecuentemente alteró la masa seca de la parte aérea.

Palabras clave: Plinia spp.; Inundación; Estrés abiótico; Frutas nativas.

\section{Introdução}

Na produção agrícola, uma das constantes preocupações está relacionada as condições climáticas de cultivo. Quando uma planta é exposta a condição de ambiente ótima ela atinge o máximo do seu potencial, ocorrendo o contrário em condição menos favorável, as plantas são impedidas de alcançarem tal potencial (Larcher, 2006; Taiz et al., 2017).

O estresse hídrico é condição que afeta o máximo crescimento e desenvolvimento das plantas. O excesso de água no solo, altera a difusão de gases, devido a redução dos espaços porosos do solo e com isso ocorre redução nos níveis de oxigênios e das trocas gasosas em níveis extremamente baixos (Jackson \& Colmer, 2005; Zabalza et al., 2008).

Os principais sintomas relacionados ao excesso de água no solo são abscisão foliar, inibição na formação de primórdios foliares, redução na expansão foliar, clorose nas folhas, 
redução no comprimento da raiz principal ou do crescimento em altura, perda da turgescência celular, morte da planta, redução da funcionalidade da cadeia transportadora de elétrons e do ciclo de Krebs (Horchani et al., 2008; Taiz et al., 2017).

A jabuticabeira (Plinia spp.), como é encontrada em vários biomas, acredita-se ter ampla plasticidade às diferentes condições edáficas. Observa-se empiricamente, que plantas irrigadas com frequência, tendem a ter mais de um ciclo de produção por ano e quando em matas, tendem a ficar próximas de ambientes próximos a condição de maior umidade de solo (Donadio, 2002; Kinupp et al, 2011). Porém, ainda não existem estudos que comprovem essa observação, em pomar e como seria para mudas em viveiro. Com base nesta premissa é necessário elucidar o comportamento da espécie frente as condições ambientais a qual a planta está exposta.

O objetivo deste trabalho foi avaliar o estresse hídrico em mudas de jabuticabeira através da inundação das plantas por diferentes períodos e lâminas de água.

\section{Metodologia}

Dois experimentos com mudas de jabuticabeira (Plinia spp.) foram realizados na Unidade de Ensino e Pesquisa Viveiro de Produção de Mudas Hortícolas e no Laboratório de Fisiologia Vegetal, da Universidade Tecnológica Federal do Paraná - Câmpus Dois Vizinhos. Para o primeiro experimento as mudas possuíam idade de aproximadamente 24 meses, e no segundo, 18 meses.

As mudas utilizadas foram transplantadas em vasos plásticos com capacidade de 3 litros, contendo substrato preparado na proporção de 2:1:1 (v/v) de latossolo, areia e cama de aviário, respectivamente. Após o transplantio, as mudas foram irrigadas e, após o estabelecimento e aclimatação em casa de vegetação $\left(25 \pm 2{ }^{\circ} \mathrm{C}\right.$ e $\left.80 \% \pm 10 \mathrm{UR}\right)$, iniciou-se o período de avaliação.

No primeiro experimento, as mudas foram colocadas em piscina plástica com dimensões de 3,0 x 1,6 m, submetidas a lâmina de água de cinco centímetros, por um período de $0,3,5,10$ e 15 dias ou por dois períodos de 3, 5, 10 e 15 dias após intervalo de 30 dias. Tal condição visou representar condição de estresse hídrico por inundação.

Os tratamentos foram constituídos da seguinte forma: T1: mudas não submetidas ao estresse; T2: mudas submetidas ao estresse por três dias; T3: mudas submetidas ao estresse por cinco dias; T4: mudas submetidas ao estresse por 10 dias; T5: mudas submetidas ao estresse por 15 dias; T6: mudas submetidas ao estresse por três dias, 30 dias sem o estresse e 
mais três dias em estresse; T7: mudas submetidas ao estresse por cinco dias, 30 dias sem o estresse e mais cinco dias em estresse; T8: mudas submetidas ao estresse por 10 dias, 30 dias sem o estresse e mais 10 dias em estresse; T9: mudas submetidas ao estresse por 15 dias, 30 dias sem o estresse e mais 15 dias em estresse.

No segundo experimento, as mudas foram inundadas por água até altura do colo, sendo acondicionada em piscina plástica com dimensões de 3,0 x 2,0 m por períodos de 0,5 , 10 e 15 dias, ou por dois períodos de 5, 10 e 15 dias após intervalo de 30 dias.

Os tratamentos foram constituídos por: T1: mudas não submetidas ao estresse; T2: mudas submetidas ao estresse por cinco dias; T3: mudas submetidas ao estresse por 10 dias; T4: mudas submetidas ao estresse por 15 dias; T5:mudas submetidas ao estresse por cinco dias, 30 dias sem o estresse e mais cinco dias em estresse; T6: mudas submetidas ao estresse por 10 dias, 30 dias sem o estresse e mais 10 dias em estresse; T7: mudas submetidas ao estresse por 15 dias, 30 dias sem o estresse e mais 15 dias em estresse.

Após 30 dias da retirada das mudas da condição de estresse, estas foram avaliadas quanto as variáveis morfológicas, fisiológicas e bioquímicas.

A taxa de sobrevivência das plantas foi determinada por meio da porcentagem de plantas vivas em relação ao total de planta.

A variáveis morfológicas: quantidade de folhas foi avaliada pela contagem total do número de folhas presentes em cada uma das mudas no início e no final da avaliação; altura total da parte aérea $(\mathrm{cm})$ da planta foi determinada através do por meio de régua graduada medido do colo até o ápice da planta, em que foram contabilizados os incrementos em altura durante o período de avaliação. Da mesma forma, o tamanho total $(\mathrm{cm})$ da planta foi avaliado do ápice da parte aérea até o comprimento final da maior raiz; diâmetro do caule (mm) medido com o auxílio de paquímetro digital a cerca de um centímetro acima do substrato, sendo verificado o incremento em relação ao crescimento inicial e final. A massa seca das raízes e da parte aérea $(\mathrm{g})$ foram determinadas em estufa com circulação forçada de ar, a 60 ${ }^{\circ} \mathrm{C}$, até massa constante. A massa da matéria seca total (g) foi realizada pela soma das duas anteriores. Com as variáveis altura, diâmetro, massa seca da parte aérea, massa seca da raiz e massa seca total, foi determinado o índice de qualidade de Dickson (IQD), segundo a metodologia de Dickson et al. (1960).

As determinações fisiológicas foram: teor de clorofila total, determinado por meio da leitura em clorofilômetro marca Falker (clorofiLOG - modelo CFL 1030) em 5 folhas de cada repetição, gerando o índice de clorofila Falker (ICF); rendimento quântico (Qy) potencial do fotossistema II foi utilizado fluorômetro da marca Photon Systems Instruments (modelo 
FluorPen FP 100), em folhas adaptadas ao escuro por 30 minutos (Strasser et al., 2000).

Para a determinação do teor de proteínas adotou-se o método de Bradford (1976), teor de açúcares totais através do método Fenol Sulfúrico (Dubois et al., 1956) e prolina foi realizada através de metodologia descrita por Bates et al. (1973), os resultados foram expressos em miligrama por grama de tecido $\left(\mathrm{mg} \mathrm{g}\right.$ de tecido $\left.{ }^{-1}\right)$ e a fenóis totais, pelo método adaptado de Bieleski \& Turner (1966) e Jennings (1981), os resultados expressos em miligrama de ácido gálico por grama de tecido (mg GAE g tecido ${ }^{-1}$ ).

O delineamento adotado foi inteiramente casualizado. Para inundação com lâmina de água de cinco centímetros (experimento 1), foram utilizados nove tratamentos com quatro repetições com 20 plantas por unidade experimental. $\mathrm{O}$ experimento 2 com inundação até a altura do coloca das mudas foi composto por sete tratamentos, com quatro repetições e 16 plantas por unidade experimental.

Os dados obtidos foram submetidos ao teste de normalidade de Lilliefors. Após os dados foram submetidos a análise de variância (ANOVA) e ao teste de comparação de médias de Duncan $(\alpha=0,05)$, utilizando-se o software GENES (Cruz, 2013) e Action Stat (Equipe Estatcamp, 2014).

As variáveis massa seca da raiz, teor de proteínas e prolina foram transformadas por $\log \mathrm{x}+1$, o índice de qualidade de Dickson e fenóis totais foram transformados por box-cox, no primeiro experimento. No último experimento, as variáveis altura da parte aérea e massa seca da raiz foram transformadas por raiz quadrada $(\sqrt{ })$ e a massa seca da parte aérea e rendimento quântico foram transformados por $\log x+1$.

\section{Resultados e Discussão}

No experimento 1, realizado com mudas de jabuticabeiras submetidas a inundação com lâmina de água de cinco centímetros, a análise de variância demonstrou para o número de folhas e diâmetro do caule, que não houve efeito significativo dos tratamentos. Para altura total da parte aérea, os tratamentos foram significativos. Para clorofila total houve efeito significativo na análise de variância. Os valores de massa seca da raiz (MSR) e da parte aérea (MSPA) e, índice de qualidade de Dickson (IQD) não foram significativos pelo teste Fisher. Em relação as variáveis teor de proteína, açúcar total, fenóis totais e prolina não houve diferença significativa entre os tratamentos.

A taxa de sobrevivência das mudas foi de 99,45\%, havendo mortalidade de uma muda, apenas no tratamento em que não foi submetido aos períodos de inundação. 
Henrique et al. (2010) ao avaliarem a sobrevivência de mudas de sibipiruna (Caesalpinia peltophoroides Benth.) verificaram que $85 \%$ das plantas com alagamento parcial sobreviveram em período de 20 dias. As plantas totalmente alagadas em 10 dias já apresentavam sobrevivência de 50\% com as condições avaliadas. $\mathrm{O}$ alagamento do solo pode afetar o crescimento e desenvolvimento das diferentes partes da planta (Medri et al., 2002).

O número de folhas observados variou entre a perda média de 1,35 folhas para o tratamento em que as mudas foram submetidas aos três dias de inundação através de lâmina de água de cinco centímetros (Tabela 1).

Tabela 1. Número de folhas (NF), altura total da parte aérea (AT) $(\mathrm{cm})$ e diâmetro do caule (DC) $(\mathrm{mm})$, clorofila total (ICF*), massa seca da raiz (MSR) (g), massa seca da parte aérea (MSPA) (g) e índice de qualidade de Dickson (IQD) para mudas de jabuticabeiras submetidas a diferentes períodos de inundação com lâmina de água de cinco centímetros.

\begin{tabular}{|c|c|c|c|c|c|c|c|c|c|c|c|c|c|}
\hline Tratamento & $\mathrm{NF}$ & & $\mathrm{AT}$ & & $\mathrm{DC}$ & & ICF & & MSR & & MSPA & IQD & \\
\hline $\mathrm{T} 1^{(1)}$ & 17,80 & $\mathrm{~ns}$ & 1,75 & $a b^{(2)}$ & 0,75 & $\mathrm{~ns}$ & 49,45 & $a b^{(2)}$ & 3,97 & $\mathrm{~ns}$ & $6,43 \quad \mathrm{~ns}$ & 1,88 & $\mathrm{~ns}$ \\
\hline $\mathrm{T} 2$ & $-1,35$ & & 1,25 & b & 0,71 & & 45,87 & $\mathrm{~b}$ & 3,73 & & 6,05 & 1,85 & \\
\hline $\mathrm{T} 3$ & 4,35 & & 1,58 & $a b$ & 0,61 & & 45,52 & $\mathrm{~b}$ & 3,90 & & 6,28 & 1,71 & \\
\hline $\mathrm{T} 4$ & 11,15 & & 1,15 & $\mathrm{~b}$ & 0,62 & & 48,91 & $a b$ & 4,55 & & 5,65 & 2,03 & \\
\hline T5 & 2,75 & & 1,45 & $\mathrm{~b}$ & 0,64 & & 46,81 & $a b$ & 4,11 & & 5,60 & 2,04 & \\
\hline T6 & 20,30 & & 2,58 & $\mathrm{a}$ & 0,83 & & 50,72 & $a b$ & 3,10 & & 6,72 & 1,57 & \\
\hline $\mathrm{T} 7$ & 21,20 & & 2,08 & $a b$ & 0,91 & & 50,15 & $a b$ & 4,53 & & 7,45 & 2,40 & \\
\hline $\mathrm{T} 8$ & 21,40 & & 2,18 & $a b$ & 0,93 & & 51,36 & $a b$ & 5,69 & & 8,23 & 2,62 & \\
\hline T9 & 24,25 & & 2,13 & $a b$ & 0,88 & & 51,99 & $\mathrm{a}$ & 3,93 & & 6,71 & 2,05 & \\
\hline C.V. (\%) & 74,02 & & 27,13 & & 25,16 & & 5,51 & & 15,02 & & 22,53 & 34,12 & \\
\hline
\end{tabular}

${ }^{(1)}$ T1: mudas não submetidas ao estresse; T2: mudas submetidas ao estresse por três dias; T3: mudas submetidas ao estresse por cinco dias; T4: mudas submetidas ao estresse por 10 dias; T5: mudas submetidas ao estresse por 15 dias; T6: mudas submetidas ao estresse por três dias, 30 dias sem o estresse e mais três dias sob estresse; T7: mudas submetidas ao estresse por cinco dias, 30 dias sem o estresse e mais cinco dias sob estresse; T8: mudas submetidas ao estresse por 10 dias, 30 dias sem o estresse e mais 10 dias sob estresse; T9: mudas submetidas ao estresse por 15 dias, 30 dias sem o

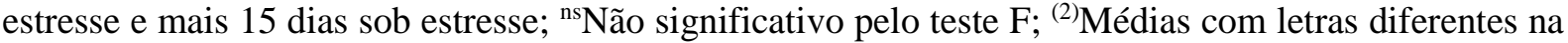
mesma coluna diferem significativamente ao nível de 5\% de probabilidade pelo teste de Duncan. *índice de clorofila Falker.

Fonte: Autores.

As respostas obtidas para o número de folhas, indicam que este não é interferido pela condição hídrica de inundação, uma vez que são mudas, e com isso, ocorre maior atividade metabólica e hormonal que interferem sobre o crescimento e impedem a ação do etileno para a senescência e abscisão. 
Research, Society and Development, v. 9, n. 11, e60591110087, 2020

(CC BY 4.0) | ISSN 2525-3409 | DOI: http://dx.doi.org/10.33448/rsd-v9i11.10087

Ao avaliar a altura da parte aérea (Tabela 1), o incremento foi superior nas mudas que passaram por dois períodos de inundação de três dias com intervalo de 30 dias entre as inundações, cujo aumento médio foi de $2,58 \mathrm{~cm}$. Porém, este tratamento não diferiu estatisticamente dos demais tratamentos em que as mudas foram submetidas aos dois períodos de inundação, bem como para as que não foram inundadas e as do período com cinco dias de inundação. O tratamento em que as mudas foram submetidas a 3 dias de inundação foi que obteve crescimento médio inferior, com 1,25 cm, seguido dos tratamentos com 10 e 15 dias de inundação, com 1,15 e 1,45 cm, respectivamente.

Os períodos de três, 10 e 15 dias com apenas um período de inundação afetaram o crescimento em altura, uma vez que se comparado aos demais, acredita-se que a planta não conseguiu ativar rotas metabólicas para que tal incremento não fosse afetado.

Bezerra et al. (2004) ao avaliarem o uso da irrigação na produção de pitangas na região Nordeste, verificaram que as plantas mostraram boa adaptação a irrigação em relação ao crescimento em altura, bem como na produção.

Para o diâmetro do caule, as médias não diferiram estatisticamente (Tabela 1). Em estudo realizado por Radaelli (2016), a jabuticabeira apresenta picos de crescimento durante seu desenvolvimento. Acredita-se que nesse momento, as mudas investiram em crescimento em altura e não em diâmetro.

Isso reforça característica que a jabuticabeira possui, em que após determinada idade, ela realiza o metabolismo de manutenção, priorizando sua sobrevivência, mesmo as condições favoráveis para o seu crescimento não sejam ideias naquele momento de estresse.

Os resultados obtidos com mudas de jabuticabeira no presente trabalho submetidas ao alagamento apontam capacidade adaptativa nos níveis mais elevados de água no solo, sendo que este não interfere no se crescimento. A manutenção do crescimento de plantas em condições de alagamento do solo depende do estado nutricional das plantas e do crescimento em altura, que pode ser utilizado como escape de efeitos nas raízes (Parolin, 2001).

Como não foi observada a morte ou perda significativa de folhas, os teores de clorofila total também não sofreram alteração significativa, em relação aos tratamentos durante o processo de avaliação. Os tratamentos submetidos aos dois períodos de $15+15$ dias inundação com intervalo de 30 dias cada, se mostrou superior em relação aos demais. Porém, não diferiram significativamente dos tratamentos de dois ciclos de $10+10$ dias, $5+5$ dias e 3 + 3 dias e, dos com apenas um ciclo de inundação de 15 e 10 dias e, sem inundação com os maiores teores nas mudas de jabuticabeira (Tabela 1).

Plântulas de Cedrela fissilis Vell. (Meliaceae) (cedro-rosa) submetidas a amplitudes e 
intensidades de inundação foram avaliadas por Binotto et al. (2016) em relação aos índices de clorofila total, em que houve aumento gradativo de acordo com o incremento no tempo de inundação. Aos 20 dias de inundação, as plantas apresentaram teor de clorofila total de 28,9 IFC, tendo aquelas do tratamento controle índice de 22,9 ICF.

Acredita-se que o teor de clorofila não seja uma das linhas de defesa das mudas de jabuticabeira em condições de estresse severo e sim as respostas obtidas no presente trabalho, nos tratamentos de três e cinco dias, favorecendo a rota metabólica provisória para síntese deste pigmento enquanto a planta se adapta. Segundo Worbes (1997), plantas em condição de alagamento, mantiveram a capacidade fotossintética, sem afetar seu desenvolvimento normal referente a produção de folhas, flores e frutos. Todavia, o que foi observado é que, nem sempre as mudas com maior teor de clorofila nas folhas, foram as que tiveram média superior para o crescimento em altura ou no acúmulo de massa seca de raiz e parte aérea (Tabelas 1 e 2).

Os valores de matéria seca (Tabela 2), não tiveram influência significativas, e variaram de 3,10 a 5,69 gramas para a raiz e entre de 5,60 a 8,23 gramas para a parte aérea.

Em plantas alagadas, a redução da massa seca quando ocorre tem relação com as raízes em maior grau se comparada com a parte aérea. Em muitos casos ocorre o desenvolvimento de raízes adventícias como forma de amenizar os problemas causados pelo alagamento (Hook \& Scholtens, 1984).

Porém, observou-se que mudas não alagadas ou com períodos pequenos de alagamento, tiverem iguais aumentos nas massas seca, tanto da raiz quanto da parte aérea que pode ser explicado pelo índice de qualidade de Dickson, no qual também não foi influenciado significativamente, já que o IQD (Tabela 1), variou entre 1,57 a 2,32, refletindo que as mudas produzidas possuem alta qualidade.

O IQD é importante, pois a muda é o insumo mais importante na implantação do pomar. Mudas produzidas com qualidade e adequadamente manejadas originam pomares produtivos e rentáveis (Pasqual et al., 2001; Chalfun \& Pio, 2002).

Nas variáveis bioquímicas avaliadas (Tabela 2), não houve diferenças significativas, para os quais o teor de proteínas variou entre 134,83 e 120,29 (mg g tecido ${ }^{-1}$ ). Os açúcares totais variaram de $0,05\left(\mathrm{mg} \mathrm{g}\right.$ tecido $\left.^{-1}\right)$ para mudas submetidas a 15 dias de inundação e 0,07 $\left(\mathrm{mg} \mathrm{g} \mathrm{tecido}^{-1}\right)$ naquelas que não foram inundadas. 
Tabela 2. Teor de proteína $\left(\mathrm{mg} \mathrm{g}\right.$ tecido $\left.{ }^{-1}\right)$, açúcar total $\left(\mathrm{mg} \mathrm{g}\right.$ tecido $\left.{ }^{-1}\right)$, fenóis totais $(\mathrm{mg}$ GAE g tecido ${ }^{-1}$ ) e prolina ( $\mathrm{mg}$ g tecido ${ }^{-1}$ ) para mudas de jabuticabeiras submetidas a diferentes períodos de inundação com lâmina de água de cinco centímetros.

\begin{tabular}{llllc}
\hline & \multicolumn{1}{c}{ Proteína } & A. total & Fenóis & Prolina \\
\hline T1 $^{(1)}$ & $126,86^{\mathrm{ns}}$ & $0,07^{\mathrm{ns}}$ & $2,62^{\mathrm{ns}}$ & $0,13 \mathrm{~ns}$ \\
$\mathrm{~T} 2$ & 120,29 & 0,06 & 2,58 & 0,10 \\
T3 & 140,34 & 0,07 & 2,14 & 0,10 \\
T4 & 126,16 & 0,07 & 2,79 & 0,10 \\
T5 & 134,40 & 0,05 & 2,77 & 0,09 \\
T6 & 133,96 & 0,07 & 2,55 & 0,07 \\
T7 & 126,31 & 0,06 & 2,73 & 0,16 \\
T8 & 134,83 & 0,06 & 2,69 & 0,14 \\
T9 & 120,67 & 0,06 & 2,73 & 0,13 \\
\hline C.V. (\%) & 2,27 & 27,15 & 42,92 & 54,12 \\
\hline
\end{tabular}

${ }^{(1)}$ T1: mudas não submetidas ao estresse; T2: mudas submetidas ao estresse por três dias; T3: mudas submetidas ao estresse por cinco dias; T4: mudas submetidas ao estresse por 10 dias; T5: mudas submetidas ao estresse por 15 dias; T6: mudas submetidas ao estresse por três dias, 30 dias sem o estresse e mais três dias sob estresse; T7: mudas submetidas ao estresse por cinco dias, 30 dias sem o estresse e mais cinco dias sob estresse; T8: mudas submetidas ao estresse por 10 dias, 30 dias sem o estresse e mais 10 dias sob estresse; T9: mudas submetidas ao estresse por 15 dias, 30 dias sem o estresse e mais 15 dias sob estresse; ns Não significativo pelo teste $\mathrm{F}$.

Fonte: Autores

Ressalta-se que os teores de proteínas e de açúcares totais não tiveram influência significativa dos tratamentos. Justificando assim o que ocorreu com as variáveis massa seca da parte aérea e da raiz pois, o metabolismo da muda não foi afetado, comprovando a plasticidade da jabuticabeira após certo período de semeadura.

Quando as plantas entram em anoxia ou hipoxia, devido a inundação do solo, podem modificar a síntese de proteínas. Quando aumentada a síntese de proteínas, que está relacionada ao metabolismo aeróbico e anaeróbico faz com que outras vias de produção sejam reduzidas ou mesmo inibidas (Lopes et al., 2005).

Em relação aos teores de açucares totais, Freitas (2015) ao avaliar plântulas de Vitex cymosa, verificou que nas folhas houve redução significativa no conteúdo destes no segundo e no sétimo dia de experimento, passando a aumentar aos 45 dias naquelas não inundadas. Nas plântulas inundadas gradativamente ocorreram a redução dos teores de açúcares solúveis totais nas folhas, sendo essa redução significativa aos 45 dias com concentração próxima a $300 \mu \mathrm{g} \mathrm{mg}^{-1}$. Tais alterações não foram verificadas nas mudas de jabuticabeira.

O teor de fenóis totais, variaram entre 2,79 e 2,14 (mg GAE g tecido $\left.{ }^{-1}\right)$ e para o teor de 
prolinas, mudas submetidas a dois períodos de três dias de inundação com lâmina de água de cinco centímetros de $0,07\left(\mathrm{mg} \mathrm{g}\right.$ tecido $\left.^{-1}\right)$ e de $0,16\left(\mathrm{mg} \mathrm{g}\right.$ tecido $\left.^{-1}\right)$ para mudas com inundação pelo período de cinco dias em dois períodos (Tabela 3).

Os teores de compostos fenólicos foram avaliados por Uriu et al. (2018) em plantas de Vochysia divergens submetidas a estação da seca e das cheias no Pantanal. Os autores verificaram que plantas submetidas a seca apresentaram maior concentração de fenóis totais, entre 131,10 e 230,94 mg de GAE g de extrato ${ }^{-1}$, em três áreas avaliadas, quando em estação das cheias os teores de fenóis variaram entre 49,32 e 87,03 mg de GAE g de extrato ${ }^{-1}$.

Estes resultados foram superiores aos observados em mudas de jabuticabeira. Caso as mudas de jabuticabeira tivessem sofrido efeitos do alagamento, estas teriam a produção de compostos fenólicos aumentado em virtude dos metabólitos secundários que seriam expressos mais ou menos em relação ao nível de estresse sofrido, agindo como defesa vegetal.

Govêa et al. (2018), ao avaliarem o teor de prolina em mudas de maracujazeiro submetida ao solo em capacidade de campo, pré-submergido e alagado, verificaram teores entre 0,04, 0,02 e 0,04 $\mu \mathrm{mol}$ prolina $\mathrm{g}^{-1}$ de material fresco, respectivamente.

Quando não ocorrem mudanças nos teores de prolina nas folhas expostas ao estresse hídrico, isto pode ser devido ao mecanismo osmorregulatório de adaptação ou em virtude da não alteração do potencial hídrico foliar a ponto de causar seu acúmulo (Pedreira et al.,2007). Tal comportamento pode ter ocorrido nas mudas de jabuticabeira.

No experimento 2 as mudas de jabuticabeiras submetidas aos períodos de inundação por $0,5,10$ e 15 dias, em um ou dois ciclos, demonstraram para as variáveis número de folhas, altura total, diâmetro do caule e massa seca da parte aérea (MSPA) influência significativas dos tratamentos. Para as variáveis massa seca da raiz e índice de qualidade de Dickson (IQD) não houve efeito significativo dos tratamentos. A variável clorofila total também não apresentou efeito significativo, diferentemente do que ocorreu com o rendimento quântico (Qy). Não houve efeito significativo entre os tratamentos para as variáveis teor de proteína, açúcar total e fenóis totais, tendo apenas com a prolina tal efeito significativo (Tabela 3). 
Tabela 3. Número de folhas (NF), altura total (AT) (cm), diâmetro do caule (DC) (mm), massa seca da raiz (MSR) (g) e massa seca da parte aérea (MSPA) (g), índice de qualidade de Dickson (IQD), Clorofila total (ICF) e rendimento quântico (Qy) para mudas de jabuticabeiras submetidas a diferentes tempos de inundação com lâmina de água a altura do colo.

\begin{tabular}{|c|c|c|c|c|c|c|c|c|}
\hline Trat & $\mathrm{NF}$ & $\mathrm{AT}$ & $\mathrm{DC}$ & MSR & MSPA & IQD & ICF & Qy \\
\hline $\mathrm{T} 1^{(1)}$ & $115,50 \mathrm{abc}$ & $5,41 \quad b$ & $2,10 \mathrm{bc}$ & $3,94^{\mathrm{ns}}$ & $6,56 \mathrm{ab}$ & $2,26^{\mathrm{ns}}$ & $42,89 \mathrm{~ns}$ & $0,76 \mathrm{ab}$ \\
\hline $\mathrm{T} 2$ & $103,38 \mathrm{bcd}$ & $3,22 \mathrm{c}$ & $1,36 \mathrm{~d}$ & 3,12 & $5,05 \mathrm{ab}$ & 2,07 & 44,74 & $0,78 \mathrm{a}$ \\
\hline $\mathrm{T} 3$ & $68,50 \mathrm{~cd}$ & $1,75 \mathrm{~d}$ & $1,64 \mathrm{~cd}$ & 2,90 & $4,72 \mathrm{ab}$ & 1,93 & 46,30 & $0,77 \mathrm{a}$ \\
\hline $\mathrm{T} 4$ & $39,81 \mathrm{~d}$ & $2,94 \mathrm{c}$ & $1,73 \mathrm{~cd}$ & 2,56 & $4,28 \mathrm{~b}$ & 1,69 & 46,74 & $0,79 \mathrm{a}$ \\
\hline $\mathrm{T} 5$ & $176,81 \mathrm{a}$ & $6,78 \mathrm{ab}$ & $2,22 \mathrm{abc}$ & 4,28 & 7,15 a & 2,38 & 47,61 & $0,73 \mathrm{~b}$ \\
\hline T6 & $132,63 \mathrm{abc}$ & $8,00 \mathrm{a}$ & $2,56 \mathrm{ab}$ & 3,32 & $5,96 \mathrm{ab}$ & 2,10 & 43,51 & $0,73 \mathrm{~b}$ \\
\hline $\mathrm{T} 7$ & $141,81 \mathrm{ab}$ & $6,72 \mathrm{ab}$ & $2,89 \mathrm{a}$ & 3,38 & 7,05 a & 2,17 & 41,33 & $0,75 \mathrm{ab}$ \\
\hline C.V. (\%) & 39,42 & 12,22 & 21,44 & 14,99 & 9,17 & 22,47 & 11,71 & 2,19 \\
\hline
\end{tabular}

${ }^{(1)}$ T1: mudas não submetidas ao estresse; T2:mudas submetidas ao estresse por cinco dias; T3: mudas submetidas ao estresse por 10 dias; T4: mudas submetidas ao estresse por 15 dias; T5: mudas submetidas ao estresse por cinco dias, 30 dias sem o estresse e mais cinco dias sob estresse; T6: mudas submetidas ao estresse por 10 dias, 30 dias sem o estresse e mais 10 dias sob estresse; T7: mudas submetidas ao estresse por 15 dias, 30 dias sem o estresse e mais 15 dias sob estresse; ${ }^{\text {ns Não }}$ significativo pelo teste F; ${ }^{(2)}$ Médias com letras diferentes na mesma coluna diferem significativamente ao nível de 5\% de probabilidade pelo teste de Duncan.

Fonte: Autores.

A utilização de dois períodos de inundação foi favorável para as variáveis de crescimento das mudas de jabuticabeira. A taxa de sobrevivência das mudas do segundo experimento foi de $100 \%$.

$\mathrm{O}$ incremento no número de folhas foi superior no tratamento em que foram aplicados dois períodos de cinco dias de inundação, com 115,50 folhas. Porém, este não diferiu estatisticamente do tratamento em que foram utilizados dois períodos de 15 dias de inundação (141,81 folhas), por dois ciclos de 10 dias (132,63 folhas) e sem a inundação (115,50 folhas). O tratamento com 15 dias em único ciclo de inundação foi de menor incremento, com 39,81 folhas (Tabela 3).

Assim como o incremento de folhas, o aumento em altura da parte aérea foi menor para as mudas submetidas a 10 dias de inundação, seguido do tratamento com 15 e cinco dias, cujo crescimento foi de 1,75 e 2,94 e 3,22 cm, respectivamente.

Binotto et al. (2016), verificaram que em plântulas de Cedrela fissilis, o número de folhas reduziu com o aumento no período de inundação, passando de 8,80 folhas para a 
testemunha a 9,50, 6,80 e 4,20 folhas nos períodos de cinco, 15 e 20 dias, respectivamente quando avaliadas 30 dias depois a inundação. Porém, após cessada tal inundação, as plântulas retomaram seu crescimento. Isso não foi observado com as mudas de jabuticabeira no presente estudo.

Kozlowski \& Pallardy (1979) relatou em seu trabalho que plantas submetidas ao alagamento reduzem o crescimento da parte aérea. Porém, este fato não foi verificado nas mudas de jabuticabeira, já que quando submetidas aos intervalos de alagamento, estes favorecem crescimento (Tabela 3).

Todavia, as maiores médias de altura total e diâmetro do caule ocorreram naquelas submetidas aos dois ciclos de inundação $(5+5,10+10$ e $15+15$ dias $)$. Se comparar tais resultados, as mudas submetidas em único ciclo, fez com que fosse ativada vias metabólicas adaptativas a partir do primeiro ciclo de inundação, ou seja, único ciclo afetou o crescimento, mas com dois, a muda conseguiu se aclimatar sem compromete-lo (Tabela 3).

Medri et al. (2012) ao avaliarem a sobrevivência de mudas de Aegiphila sellowiana Cham, em condições de alagamento, verificaram que em 10 dias nesta condição, 33,3\% das plantas estavam mortas. Estes mesmos autores, verificaram que o crescimento do diâmetro do caule foi menor em plantas alagadas, bem como, a abscisão foliar, sendo ao contrário do que foi observado em plantas submetidas a condição de solo drenado.

A massa seca da raiz e o índice de qualidade de Dickson não apresentaram efeito significativo dos tratamentos, cujas médias foram de 1,72 gramas e 2,09, respectivamente (Tabela 3). Para a massa seca da parte aérea, os tratamentos em que as mudas foram submetidas a dois ciclos de inundação de cindo e quinze dias, respectivamente, apresentaram o maior incremento. O tratamento com 15 dias de inundação a massa seca foi de 4,28 gramas (Tabela 3).

Pimenta (1998) verificou que a guabirobeira (Campomanesia xanthocarpa) teve seu metabolismo reestabelecido após períodos de alagamento o que possibilitou a retomada do desenvolvimento normal das plantas. Isso pode ter ocorrido nos tratamentos que as médias tiveram superioridade para altura e diâmetro (Tabela 3).

O teor de clorofila não foi influenciado significativamente pelos tratamentos, tendo médias entre 41,33 e 47,61 ICF. Tal resposta reforça que a síntese de clorofila não tem seu metabolismo afetado pela inundação.

Os valores de rendimento quântico foram superiores nas mudas submetidas em apenas único ciclo (cinco, 10 e 15 dias), em dois ciclos de 15 dias cada e sem a inundação (Tabela 3).

O rendimento quântico foi superior nas mudas em que foram submetidas em apenas 
um ciclo de inundação, com períodos de cinco, 10 e 15 dias, cujos valores foram de 0,78, 0,77 e 0,77, respectivamente. Observa-se, porém, que apesar de serem estatisticamente diferentes, as médias ficaram entre 0,73 e 0,79 , em que as menores médias foram para mudas mantidas por cinco e 10 dias de inundação em dois ciclos por igual período (Tabela 4).

O rendimento quântico (Qy) tem sido utilizado para identificar problemas no sistema fotossintético após estresses abióticos e bióticos. Melo et al. (2010) avaliaram lâminas de irrigação de 40; 70; 100; e 130\% da evapotranspiração de referência (ETo), verificando que para $100 \%$ de ETo, o rendimento quântico foi de 0,79 elétron quantum ${ }^{-1}$, sendo reduzido nas condições de $40 \%$ e $130 \%$, na proporção de $5,36 \%$ e $8,81 \%$, respectivamente.

Como o incremento em altura e diâmetro, bem como, a massa seca da parte aérea e número de folhas (Tabela 4) não foram comprometidas pelos valores de rendimento quântico obtido nos tratamentos de menor média, ciclos de cinco + cinco e $10+10$, acredita-se que pode ter ocorrido fotoinibição em alguns momentos e que rapidamente foi superada pois se não tivesse ocorrido isso não teria médias com superioridade estatística.

O fechamento estomático, danos no fotossistema II e a diminuição na fotossíntese também são respostas comuns à deficiência de oxigênio no solo causada pelo alagamento. Limitações estomáticas e não estomáticas são responsáveis pelo decréscimo na fotossíntese (Kozlowski; Pallardy, 1979).

O teor de proteína obtido nas mudas de jabuticabeira submetidas aos períodos de inundação variou de 231,84 a 313,06 (mg g tecido-1 ${ }^{-1}$. O açúcar total variou de 0,05 a 0,07 (mg $\left.\mathrm{g}_{\text {tecido }}{ }^{-1}\right)$, nos tratamentos que foram aplicados um período de inundação de três e cinco dias, não diferindo significativamente em ambas as variáveis, respectivamente (Tabela 4). 
Tabela 4. Teor de proteína $\left(\mathrm{mg} \mathrm{g}\right.$ tecido $\left.{ }^{-1}\right)$, açúcar total $\left(\mathrm{mg} \mathrm{g} \mathrm{tecido}^{-1}\right)$, fenóis totais $(\mathrm{mg} \mathrm{GAE}$ $\mathrm{g}$ tecido $\left.^{-1}\right)$ e prolina $\left(\mathrm{mg} \mathrm{g} \mathrm{tecido}^{-1}\right)$ em mudas de jabuticabeiras submetidas a diferentes tempos de inundação com lâmina de água a altura do colo.

\begin{tabular}{|c|c|c|c|c|c|c|c|c|}
\hline & \multicolumn{2}{|l|}{ Proteína } & \multicolumn{2}{|c|}{ Aç. Total } & \multicolumn{2}{|c|}{ Fenóis } & \multicolumn{2}{|c|}{ Prolina } \\
\hline $\mathrm{T} 1^{(1)}$ & 308,52 & $\mathrm{~ns}$ & 0,07 & ns & 2,55 & ns & 0,17 & $a b^{(2)}$ \\
\hline $\mathrm{T} 2$ & 286,59 & & 0,06 & & 2,60 & & 0,07 & $\mathrm{c}$ \\
\hline $\mathrm{T} 3$ & 231,84 & & 0,06 & & 2,61 & & 0,14 & $\mathrm{bc}$ \\
\hline $\mathrm{T} 4$ & 305,55 & & 0,07 & & 2,60 & & 0,23 & $\mathrm{a}$ \\
\hline T5 & 304,77 & & 0,05 & & 2,65 & & 0,08 & $\mathrm{c}$ \\
\hline T6 & 313,06 & & 0,07 & & 2,42 & & 0,11 & $\mathrm{bc}$ \\
\hline $\mathrm{T} 7$ & 292,23 & & 0,06 & & 2,43 & & 0,09 & $\mathrm{bc}$ \\
\hline C.V. $(\%)$ & 13,37 & & 15,61 & & 4,48 & & 45,21 & \\
\hline
\end{tabular}

${ }^{(1)}$ T1: mudas não submetidas ao estresse; T2: mudas submetidas ao estresse por cinco dias; T3: mudas submetidas ao estresse por 10 dias; T4: mudas submetidas ao estresse por 15 dias; T5:mudas submetidas ao estresse por cinco dias, 30 dias sem o estresse e mais cinco dias sob estresse; T6: mudas submetidas ao estresse por 10 dias, 30 dias sem o estresse e mais 10 dias sob estresse; T7: mudas submetidas ao estresse por 15 dias, 30 dias sem o estresse e mais 15 dias sob estresse; ${ }^{\text {ns Não }}$ significativo pelo teste F; ${ }^{(2)}$ Médias com letras diferentes na mesma coluna diferem significativamente ao nível de 5\% de probabilidade pelo teste de Duncan.

Fonte: Autores.

Os teores de proteínas, açúcares totais e fenóis apresentaram mesma resposta de não significância dos tratamentos nas mudas de jabuticabeira, não consumindo maior quantidade de reservas ou não ativando rotas metabólicas de forma diferenciada com os distintos tempos de inundação.

Plantas submetidas a ambientes alagados, reduzem a taxa de respiração, desta forma acumulam açúcares solúveis e alteram o metabolismo associado a alocação de biomassa (Maurenza et al., 2009; Qin et al., 2013).

Belo et al. (2015) ao avaliarem a influência de períodos de 0, 3, 6, 9, 12, 15 e 18 dias de alagamento em guabirobeira observaram redução significativa no teor de proteína devido ao estresse hídrico, após seis dias nesta condição, mas aos 12 dias tais teores voltaram a aumentar. Essa redução pode ser atribuída a redução na disponibilidade de aminoácidos ou desnaturação enzimática envolvidos na resposta ao estresse.

A quantidade de fenóis (Tabela 4) também não teve influência significativa dos tratamentos de inundação em que as mudas de jabuticabeira foram submetidas. Os teores de prolina (Tabela 4) foram superiores nos tratamentos em que as mudas de jabuticabeira foram submetidas apenas 15 dias de inundação e sem tal condição abiótica. 
Research, Society and Development, v. 9, n. 11, e60591110087, 2020

(CC BY 4.0) | ISSN 2525-3409 | DOI: http://dx.doi.org/10.33448/rsd-v9i11.10087

Assim como ocorreu no experimento anterior, acredita-se que os períodos em que as mudas de jabuticabeira foram mantidas em inundação não foram suficientes para ativar as vias metabólicas secundárias envolvidas com a defesa vegetal pelos fenóis, mesmo visualizado no rendimento quântico efeito sobre o fotossistema II.

Quando avaliados os resultados dos dois experimentos em que as mudas foram submetidas a lâminas de inundação, verificou-se que o impacto do alagamento foi menor nas submetidas a lâmina de cinco centímetros de água. Estes resultados sugerem que as mudas não sofreram com a alteração do meio. As variáveis analisadas não tiveram influência dos tratamentos sobre os resultados obtidos.

Quando submetidas aos níveis de inundação maiores, as mudas tiveram incremento de crescimento em folhas, altura da muda e diâmetro do caule com resultados significativos, cujas superioridades foram observadas nos tratamentos que a muda foi submetida aos dois ciclos de inundação.

Da mesma forma, em ambos os experimentos, as variáveis bioquímicas não foram significativas com a aplicação dos tratamentos, apenas para os teores de prolina que se alteraram, com a inundação até o colo da planta.

\section{Considerações Finais}

O crescimento das mudas de jabuticabeira não foi afetado pelos períodos de inundação adotados para os experimentos com diferentes capacidades de campo.

Nos tratamentos em que as plantas foram submetidas aos dois ciclos de inundação com lâmina de água a altura do colo apresentaram diferenças significativas no incremento em número de folhas, altura da muda e diâmetro do caule o que consequentemente alterou a massa seca da parte aérea.

O rendimento quântico avaliado, ficou próximo ao limite para causar danos ao fotossistema II nas mudas submetidas a inundação com lâmina de água a altura do colo.

As variáveis bioquímicas, proteínas, açúcares totais e fenóis totais não foram influenciadas pela porcentagem de água no substrato, bem como para aquelas submetidas a inundação com lâmina de água de cinco centímetros.

Em mudas submetidas a períodos de inundação a altura do colo houve alteração nos teores de prolina. 


\section{Referências}

Bates, L. S., Waldern, R. P., \& Teare, I. D. (1973). Rapid determination of free proline for water stress studies. Plant and Soil. 39,205-207. doi: 10.1007/BF00018060

Belo, E. S., Costa Netto, A. P., Stein, V. C. S., \& Silva, S. M. G. (2015) Impact of drought and flooding stresses on Gabiroba plants. Revista de Ciências Agrárias. 58(4) 379-387. doi: 10.4322/rca.1952

Bezerra, J. E. F., Lederman, I. E., Silva Júnior, J. F., \& Alves, M. A. (2004). Comportamento da pitangueira (Eugenia uniflora L.) sob irrigação na região do Vale do Rio Moxotó, Pernambuco. Revista Brasileira de Fruticultura. 26(1), 177- 179. doi: 10.1590/S010029452004000100047

Bieleski, R. L., \& Turner, N. A. (1966). Separation and estimation of amino acids in crude plant extratcts by thin-layer electrophoresis and chomatograghy. Analitycal Biochemistry. 17, 278-293. doi: 10.1016/0003-2697(66)90206-5

Binotto, B., Antoniazzi, A. P., Neumann, G. M., Sausen, T. L., \& Budke, J. C. (2016). Tolerância de plântulas de Cedrela fissilis Vell. a diferentes amplitudes e intensidades de inundação. Ciência Florestal, 26(4), 1339-1348. doi: 10.5902/1980509825153

Bradford, M. M. (1976). A rapid and sensitive method for the quantitation of microgram quantities of protein utilizing the principle of protein-dye binding. Analytical Biochemistry. 72, 248-254. doi: 10.1016/0003-2697(76)90527-3

Chalfun, N. N. J., \& Pio, R. (2002). Aquisição e plantio de mudas frutíferas. Lavras: UFLA, $19 \mathrm{p}$.

Cruz, C. D. (2013). Programa GENES: aplicativo computacional em genética e estatística (software). Viçosa: Imprensa Universitária, 442p.

Dickson, A., Leaf, A. L., \& Hosner, J. F. (1960). Quality appraisal of white spruce and white pine seedling stock in nurseries. Forest Chronicle. 36(1), 10-13. 
Donadio, L. C. (2000). Jabuticaba (Myrciaria jaboticaba (Vell.) Berg). Jaboticabal: FUNEP, $55 \mathrm{p}$.

Dubois, M., Gilles, K. A., Hamilton, J. K., Rebers, P. A., \& Smith, F. (1956). Colorimetric method for determination of sugars and related substances. Analitycal Biochemistry. 28, 350356. doi: 10.1021/ac60111a017

Equipe Estatcamp. (2014). Software Action. Estatcamp - Consultoria em estatística e qualidade, São Carlos 2014

Freitas, F. C. (2015) Respostas morfofisiológicas de plântulas de Vitex cymosa bertero ex spreng. (Lamiaceae) à inundação artificial. Dissertação (Mestrado em Diversidade Biológica) - Universidade Federal do Amazonas, Manaus.

Govêa, K. P., Cunha Neto A. R., Resck, N. M., Moreira, L. L., Veroneze Júnior, V., Pereira, F. L., Polo, M., \& Souza, T. C. (2018). Morpho-anatomical and physiological aspects of Passilora edulis Sims (passion fruit) subjected to looded conditions during early developmental stages Biotemas. 31(3), 15-23. doi: 10.5007/2175-7925.2018v31n3p15

Henrique, P. C., Alves, J. D., Goulart, P. F. P., Deuner, S., Silveira, N. M., Zanandrea, I., \& Castro, E. M. (2010). Physiological and anatomical characteristics of Sibipiruna plants under hipoxia. Ciência Rural. 40(1), 70-76. doi: 10.1590/S0103-84782009005000221

Hook, D. D., \& Scholtens, J. R. (1978). Adaptations and flood tolerance of tree species. In: Hook, D. D., Crawford, R. M. M. Plant Life in Anaerobic Environments, Michigan: Ann Arbor Science. 299-331.

Horchani, F., Gallusci, P., \& Baldet, P. (2008). Prolonged root hypoxia induces ammonium accumulation and decreases the nutritional quality of tomato fruits Journal of plant physiology. Journal of Plant Physiology. 165(13), 1352-1359. doi: 10.1016/j.jplph.2007.10.016

Jackson, M. B., \& Colmer, T. D. (2005). Response and adaptation by plants to flooding stress. 
Annals of Botany. 96, 501-505. doi:10.1093/aob/mci205

Jennings, A. C. (1991). The determination al dihydroxy phenolic compounds in extracts of plant tissues. Analitycal Biochemistry. 118, 396-398. doi: 10.1016/0003-2697(81)90600-X

Kinupp, V. F., Lisbôa, G. N., \& Barros, I. B. I. (2011). Plinia peruviana, Jabuticaba. In: Coradin, L., Siminski, A., \& Reis, A. Espécies Nativas da Flora Brasileira de Valor Econômico Atual ou Potencial: Plantas para o Futuro - Região Sul. Brasília: MMA. 934p.

Kozlowski, T. T., \& Pallardy, S. G. (1979). Stomatal response of Fraxinus pennsylvanica seedlings during and after flooding. Physiologia Plantarum. 46(2), 155-158. doi: 10.1111/j.1399-3054.1979.tb06549.x

Larcher, W. (2006). Ecofisiologia Vegetal, São Carlos: Rima. 550p.

Lopes, M. J. C., Souza, I. R. P., Magalhães, P. C., Gama, E. E. G., Alves, J. D., \& Magalhães, M. M. (2005). Oxidação protéica e peroxidação lipídica em plantas de diferentes ciclos de seleção do milho 'saracura', sob encharcamento contínuo. Revista Brasileira de Milho e Sorgo. 4(3), 362-373. doi: 10.18512/1980-6477/rbms.v4n3p362-373

Maurenza, D., Marenco, R. A., \& Piedade, M. T. F. (2009). Efeito da inundação de longa duração sob o crescimento de Pouteria glomerata (Sapotaceae), uma arbórea da várzea da Amazônia Central. Acta Amazonica, 39(3), 519-526. doi: 10.1590/S004459672009000300005

Medri, C., Pimenta, J. A., Ruas, E. A., Souza, L. A., Medri, O. S., \& Sayhun, S. (2012). O alagamento do solo afeta a sobrevivência, o crescimento e o metabolismo de Aegiphila sellowiana Cham. (Lamiaceae). Semina: Ciências Biológicas e da Saúde. 33(1), 123-134. doi: $10.5433 / 1679-0367.2012 \mathrm{v} 33 \mathrm{n} 1 \mathrm{p} 123$

Medri, M. E., Bianchini, E., Pimenta, J. A., Colli, S., Muller, C. (2002). Estudos sobre a tolerância ao alagamento em espécies arbóreas nativas da bacia do rio Tibagi. In: Medri, M. E., Bianchini, E., Shibatta, O. A., Pimenta, J. A. (Ed.). A bacia do Rio Tibagi. Londrina: Edição dos editores, p. 133-172. 
Melo, A. S., Suassuna J. F., Fernandes P. D., Brito, M. E. B., Suassuna, A. F., \& Aguiar Netto, A. O. (2010). Crescimento vegetativo, resistência estomática, eficiência fotossintética e rendimento do fruto da melancieira em diferentes níveis de água. Acta Scientiarum Agronomy. 32(1), 73-79. doi: 10.4025/actasciagron.v32i1.213610.4025/actasciagron.v32i1.2136

Parolin, P. (2001). Morphological and physiological adjustments to waterlogging and drought in seedlings of Amazonian floodplain trees. Oecologia. 128, 326-335. doi: $10.1007 / \mathrm{s} 004420100660$

Pasqual, M., Chalfun, N. N. J., Ramos, J. D., Vale, M. R., \& Silva, C. R. R. (2001). Fruticultura comercial: propagação de plantas frutíferas. Lavras: UFLA/FAEPE, 137 p.

Pedreira, A. C., Maia, P. S. P., Oliveira Neto, C. F., Castro, D. S., Freitas, J. M. N, Lobato, A. K. S., \& Costa, R. C. L. (2007). Conteúdo relativo de água, teor de prolina e carboidratos solúveis totais em folhas de duas cultivares de milho submetidas a estresse hídrico. Revista Brasileira de Biociências. 5(2), 918-920.

Pimenta, J. A. (1998). Estudo populacional de Campomanesia xanthocarpa O. Berg (Myrtaceae) no Parque Estadual Mata dos Godoy, Londrina, PR. Tese (Doutorado em Ciências Biológicas) - Universidade Estadual de Campinas, Campinas, 1998.

Qin, X., Li, F., Chen, X., \& Xie, Y. (2013). Growth responses and non-structural carbohydrates in three wetland macrophyte species following submergence and desubmergence. Acta Physiologiae Plantarum. 35(7), 2069-2074. doi: 10.1007/s11738-013$1241-\mathrm{x}$

Radaelli, J. C. (2016). Seleção de jabuticabeiras juvenis considerando o vigor, o potencial antioxidante e a tolerância a geadas. Dissertação (Mestrado em Agronomia) - Universidade Tecnológica Federal do Paraná, Pato Branco, 2016.

Strasser, R. J., Srivastava, A., \& Tsimilli-Michael, M. (2000). The fluorescence transient as a tool to characterize and screen photosynthetic samples, In: Yunus, M., Pathre, U., \& Mohanty, P. (Eds.). Probing Photosynthesis: Mechanism, regulation and adaptation. New York: Taylor 
and Francis. 445-483.

Taiz, L., Zeiger, E., Moller, I. \& Murphy, A. (2017). Fisiologia e desenvolvimento vegetal. 6.ed. Porto Alegre: Artmed, 888p.

Uriu, D. D., Godoy, B. S. A., Battirola, L. D., Andrighetti, C. R., Marques, M. I. \& Valladao, D. M. S. (2017). Temporal variation of the total phenolic compounds concentration in Vochysia divergens Pohl. (Vochysiaceae) leaves in the brazilian pantanal. Revista Árvore. 41(3), e410316. doi: 10.1590/1806-90882017000300016

Worbes, M., Klinge, H., Revilla, J. D. \& Martius, C. (1992). On the dynamics, floristic subdivision and geographical distribution of varzea forest in central Amazonia. Journal of Vegetable Science. 3, 553-564. doi: 10.2307/3235812

Zabalza, A., Dongen, J. T. V., Froehlich, A., Oliver, S. N., Faix, B., Gupta, K. J., Schmälzlin, E., Igal, M., Orcaray, L., Royuela, M. \& Geigenberger, P. (2008). Regulation of respiration and fermentation to control the plant internal oxygen concentration. Plant Physiology, 149, 1087-1098. doi: 10.1104/pp.108.129288

\section{Porcentagem de contribuição de cada autor no manuscrito}

$$
\begin{gathered}
\text { Juliana Cristina Radaelli }-40 \% \\
\text { Karina Guollo }-10 \% \\
\text { Carlos Kosera Netto }-10 \% \\
\text { Marciéli da Silva }-10 \% \\
\text { Fabiano Simões }-10 \% \\
\text { Américo Wagner Júnior }-20 \%
\end{gathered}
$$

